\title{
Interpreting concealed questions
}

\author{
Maria Aloni · Floris Roelofsen
}

Published online: 1 March 2012

(C) The Author(s) 2012. This article is published with open access at Springerlink.com

\begin{abstract}
Concealed questions are determiner phrases that are naturally paraphrased as embedded questions (e.g., John knows the capital of Italy $\approx$ John knows what the capital of Italy is). This paper offers a novel account of the interpretation of concealed questions, which assumes that an entity-denoting expression $\alpha$ may be type-shifted into an expression ?z.P( $\alpha)$, where $P$ is a contextually determined property, and $z$ ranges over a contextually determined domain of individual concepts. Different resolutions of $P$ and the domain of $z$ yield a wide range of concealed question interpretations, some of which were not noted previously. On the other hand, principled constraints on the resolution process prevent overgeneration.
\end{abstract}

Keywords Concealed question - Quantification under conceptual cover · Context-dependence

\begin{abstract}
Previous versions of this paper have been presented at SALT in 2008, at the Frequently Asked Concealed Questions workshop organized by Ilaria Frana, Magdalena Schwager, and Sarah Zobel in Göttingen in June 2009, at the Focus on Discourse and Context-Dependence workshop organized by Kata Balogh in Amsterdam in September 2009, during a seminar on implicit content organized by Barbara Partee in Amherst in November 2009, and at a symposium on the occasion of the PhD-defense of Radek Šimík in Groningen in February 2011. We are very grateful to the audiences at these events, and in particular to Rajesh Bhatt, Kai von Fintel, Ilaria Frana, Jeroen Groenendijk, Jesse Harris, Irene Heim, Cécile Meier, Lance Nathan, Barbara Partee, Maribel Romero, Magdalena Schwager, Matthijs Westera, and two anonymous reviewers for very useful feedback. The research reported here was made possible by financial support from the Netherlands Organization for Scientific Research (NWO), which is gratefully acknowledged.
\end{abstract}

M. Aloni · F. Roelofsen ( $\square)$

University of Amsterdam, Amsterdam, The Netherlands

e-mail: floris.roelofsen@gmail.com

M. Aloni

e-mail: m.d.aloni@uva.nl 


\section{Introduction}

Concealed questions (CQs) are determiner phrases (DPs) which are naturally paraphrased as questions. ${ }^{1}$

(1) John knows the capital of Italy.

$\approx$ John knows what the capital of Italy is.

(2) They revealed the winner of the contest.

$\approx$ They revealed who the winner of the contest was.

Concealed questions arise not only with definite DPs, but also with indefinite and quantified ones.

(3) John knows a doctor who could help you.

(Frana 2006)

(4) John knows every phone number.

(Heim 1979)

Heim (1979) observed that quantified CQs exhibit an interesting ambiguity. If no particular context is given, the most salient reading of (4) is probably what we will call the specificational reading:

(5) John knows that Ann's number is 503, that Bill's number is 431, etc.

But if John's task is to assign to every newly installed phone a number that is not yet taken by any other phone, then he doesn't need to "know every phone number" in the sense of knowing which phone number is whose, but merely in the sense of knowing which numbers are somebody's at all (Heim 1979, p. 60). We call this the predicational reading ${ }^{2}$ :

(6) John knows of every phone number whether it is a phone number.

Predicational readings are particularly salient when the CQ noun is non-relational. This is illustrated by the following variant of Heim's original example, provided by Matthijs Westera (p.c.):

(7) John knows every prime number.

Apart from the basic definite, indefinite and quantified CQs exemplified in (1)-(4), there are also structurally more involved cases like:

\footnotetext{
${ }^{1}$ Sentence (1) and many of the other examples to be discussed below have, besides the described CQ reading, also an acquaintance reading. In languages like Italian and Dutch, where epistemic know and acquaintance know are lexically distinct, the CQ reading can be forced by using the verb for epistemic know (sapere in Italian and weten in Dutch).

${ }^{2}$ In Roelofsen and Aloni (2008) we referred to specificational and predicational readings as pair-list and set-readings, respectively. The intended interpretation of the terms has not changed; we have just come to find specificational and predicational more appropriate.
} 
John knows the capital that Fred knows.

Heim (1979) observed that such CQ-containing CQs (CCQs) are ambiguous. In particular, she noted that (8) has the following two readings, which are generally referred to in the literature as Reading $\mathrm{A}$ and Reading $\mathrm{B}:^{3}$

(9) Reading A:

There is exactly one country $x$ such that Fred can name $x$ 's capital; and John can name $x$ 's capital as well.

(10) Reading B:

John knows which country $x$ is such that Fred can name $x$ 's capital (although John may be unable to name $x$ 's capital himself).

Suppose Fred knows that the capital of Italy is Rome. Then on Reading A, (8) entails that John also knows that the capital of Italy is Rome. On Reading B, (8) lacks this entailment. It only follows that John knows that Fred can name the capital of Italy.

Of course, CCQs may also be indefinite or quantified:

(11) John knows a doctor that Fred knows.

(12) John knows every capital that Fred knows.

This paper provides a unified account of the interpretation of definite, indefinite, and quantified CQs and CCQs. In developing such an account, we will considerably widen the empirical domain. In particular, among other things, we will show that the $\mathrm{A}$ and $\mathrm{B}$ readings described above are just two among many readings that may arise for CCQs.

The paper is organized as follows. Section 2 provides a brief overview of the theoretical options that have been explored in the recent literature, and points out what we think is the most promising direction to take. Section 3 identifies some outstanding problems, and Section 4 develops a new account of the interpretation of CQs that resolves these problems. In the Appendix, we outline an account of the distribution of CQs in comparison with full-fledged declarative and interrogative complement clauses, and we briefly discuss two remaining issues for our theory of CQ interpretation.

\section{Recent approaches}

As depicted in Fig. 1, recent approaches differ along two dimensions. Along the vertical dimension, which we call the TYPE dimension, theories differ in that they

\footnotetext{
${ }^{3}$ For simplicity, we disregard the distinction between what is presupposed and what is asserted in paraphrasing these readings. We will continue to do so throughout the paper.
} 


\begin{tabular}{l|ll} 
Propositions & $\begin{array}{l}\text { Romero, 2007 } \\
\text { Nathan, 2006 }\end{array}$ & Aloni, 2008 \\
Properties & Frana, 2006 & Schwager, 2007 \\
& Romero, 2005 & Schwager, 2007 \\
$\begin{array}{l}\text { Individual } \\
\text { concepts }\end{array}$ & & \\
\cline { 2 - 3 } & [-perspective] & [+perspective]
\end{tabular}

Fig. 1 An overview of recent approaches

assign different semantic types to CQs. Some take CQs to denote propositions, while others take them to denote properties or individual concepts. Along the horizontal dimension, which we call the PERSPECTIVAL dimension, theories differ in that some take the interpretation of CQs to be dependent on a particular perspective that is taken on the individuals in the domain of discourse, while others do not (what this means exactly will be explained right below). ${ }^{4}$

Along the TYPE dimension, there are two basic arguments. The first involves coordination. CQs can be coordinated with full-fledged declarative and interrogative complement clauses, as in (13) and (14).

(13) They revealed the winner of the contest and that the President of the association would hand out the prize in person.

(14) I only knew the capital of Italy and who won the World cup in 1986.

If $\mathrm{CQs}$ are taken to denote propositions, then these coordination facts can be straightforwardly accounted for. This is immediately clear in the case of (13), which involves coordination of a CQ with a declarative complement clause. Declarative complement clauses are standardly taken to denote propositions. Thus, if CQs are also taken to denote propositions, the meaning of the coordinate structure in (13) is straightforwardly derived.

The CQ in (14) is coordinated with an interrogative complement clause. If CQs are taken to denote propositions, and if interrogative complement clauses are taken

\footnotetext{
4 After this paper was submitted for publication (in November 2009) the individual concept approach of Romero (2005) was further developed by Frana (2010a, b) and Romero (2010), while Percus (2010) proposed an account on which CQs denote sets of propositions. Several issues that will be addressed in the present paper have also been addressed in this more recent work, in a rather different way. We will provide some specific pointers throughout the paper, but a detailed comparison must be left for another occasion.

An earlier contribution that is missing from the chart is that of Harris (2007). Harris' work certainly belongs in the [+perspective] column, but it does not belong in any of the rows in the chart. Harris analyzes CQs as functions from individual concepts to identity questions, or, equivalently, as functions from worldpairs to sets of individual concepts.
} 
to denote propositions as well, as for instance assumed by Groenendijk and Stokhof (1984) and Aloni (2008), then the meaning of the coordinate structure in (14) is again straightforwardly derived. If instead interrogative complement clauses are taken to denote sets of propositions, as for instance assumed by Karttunen (1977a), the meaning of the coordinate structure in (14) could still be derived in a rather straightforward way, assuming the existence of an operator that takes an interrogative clause and delivers the true exhaustive answer to the question expressed by that interrogative clause in the world of evaluation (e.g., the $\mathrm{ANS}_{2}$ operator in Heim 1994). Under the assumption that interrogative complement clauses denote sets of propositions, such an operator would be independently needed to derive the meaning of sentences like:

Julia remembers what Ben ate and that he didn't like it.

Thus, if CQs are taken to denote propositions, the meaning of sentences like (13) and (14) can be derived without stipulating ad hoc type-shifting operators. Evidently, this is not the case if CQs are taken to denote properties or individual concepts, rather than propositions.

The other argument along the TYPE dimension is one of parsimony. All CQ-embedding verbs also embed full-fledged interrogative and/or declarative clauses. Thus, if CQs are taken to denote propositions, CQ-embedding verbs can be composed with their CQ-complements just as they would be composed with their full-fledged interrogative and/or declarative complements. If CQs are not taken to denote propositions but, say, individual concepts, then CQ-embedding verbs must be associated with at least two distinct lexical items: one which embeds proposition denoting expressions and one which embeds individual concept denoting expressions. Clearly, such stipulations should be avoided whenever possible. Thus, both arguments along the TYPE dimension favor approaches that take CQs to denote propositions.

Now let us turn to the horizontal dimension in Fig. 1. Along this dimension, theories differ in that some take the interpretation of CQs to be dependent on a particular perspective that is taken on the individuals in the domain of discourse, while others do not. What this means exactly is best explained by means of an example.

Suppose that in front of you lie two face-down cards. One is the Ace of Hearts, the other is the Ace of Spades, but you don't know which is which. You have to choose one card: if you choose the Ace of Hearts you win $€ 10$, if you choose the Ace of Spades you lose $€ 10$. Now consider the following sentence:

You know the winning card.

Is this sentence true or false in the given situation? On the one hand, the sentence is true: you know that the Ace of Hearts is the winning card. On the other hand, the sentence is false: as far as you know, the winning card may be the card on the left, but it may just as well be the card on the right. Intuitively, there are two ways in which the cards may be identified in this situation: by their position (the card on the 
left, the card on the right) or by their suit (the Ace of Hearts, the Ace of Spades). Whether (16) is judged true or false depends on which of these perspectives is adopted. If identification by suit is adopted, the sentence is judged true. But if identification by position is adopted, the sentence is judged false. Some theories of CQs account for such perspective-related ambiguities, others do not. Clearly, other things being equal, the ones that do are to be preferred.

This leads us to the preliminary conclusion that Aloni's (2008) theory, which takes CQs to denote propositions and accounts for perspective-related ambiguities, is the most promising theory among those proposed in the recent literature. Several problems remain however. In the next section, we discuss Aloni's theory and the problems it faces.

\section{Concealed questions under cover}

Aloni's theory of CQs builds on the theory of questions developed in (Aloni 2001). This in turn is an extension of Groenendijk and Stokhof's (1984) theory of questions, one which is especially geared at capturing the perspective-sensitive nature of questions and other operators in natural language. We will first review Aloni's approach to questions in general. Then we will turn to her account of CQs in particular, and point out some of its shortcomings.

\subsection{Conceptual covers}

Consider again the card situation discussed in the previous section. In front of you lie two face-down cards. One is the Ace of Spades, the other is the Ace of Hearts. You don't know which is which. There are two different ways of identifying the two cards in this scenario: by their position on the table (the card on the left, the card on the right) and by their suit (the Ace of Spades, the Ace of Hearts). Aloni (2001) proposes to formalize such methods of identification in terms of conceptual covers. A conceptual cover is a set of individual concepts which exclusively and exhaustively covers the domain of individuals: each individual is identified by exactly one concept in each world. More formally:

Definition 1 (Conceptual covers) Given a set of possible worlds $W$ and a domain of individuals $D$, a conceptual cover $C C$ based on $(W, D)$ is a set of functions $W \rightarrow D$ such that:

$$
\forall w \in W: \forall d \in D: \exists ! c \in C C: c(w)=d
$$

Illustration To formalize the card situation discussed above we need a model with two worlds, $w_{1}$ and $w_{2}$, and a domain consisting of two individuals, $\varnothing$ and $\mathbf{A}$. As illustrated in the diagram below, either $\varnothing$ is the card on the left (in $w_{1}$ ) or it is the card on the right (in $w_{2}$ ).

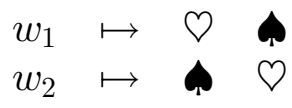


There are only two possible conceptual covers definable over such a model, namely the set A which identifies the cards by their position and the set B which identifies the cards by their suit:
$\mathrm{A}=\{$ the card on the left, the card on the right $\}$
$\mathrm{B}=\{$ the Ace of Spades, the Ace of Hearts $\}$

C below is a set of concepts which does not constitute a conceptual cover:

$\mathrm{C}=\{$ the card on the left, the Ace of Hearts $\}$

For $\mathrm{C}$ to be a conceptual cover, every individual should instantiate exactly one concept in every world. But this is not the case. In $w_{1}$ for example, $\varnothing$ instantiates two concepts, while does not instantiate any concept at all.

\subsection{Quantification under cover}

We start with a language of first-order logic enriched with a $l$-operator and a question operator '?'. A model for this language is a quadruple $(W, D, I, C)$ where $W$ is a set of possible worlds, $D$ a set of individuals, $I$ a world dependent interpretation function, and $C$ a set of conceptual covers based on $(W, D)$. Sentences are evaluated relative to a model, a world in that model, and an assignment function. Normally, an assignment function $g$ simply maps a variable $x$ to some individual $d \in D$. However, in Aloni's framework, variables do not range over individuals simpliciter, but rather over the elements of some pragmatically determined conceptual cover. The conceptual cover that a variable $x$ ranges over is determined by a cover resolution function $\mathcal{R}$. This function maps every variable $x$ to some conceptual cover in $C .^{5}$

Definition 2 (Cover resolution functions) Given a set of variables $V$ and a model $(W, D, I, C)$, a cover resolution function $\mathcal{R}$ is a function that maps every variable $x$ in $V$ to some conceptual cover in $C$.

Now, given a certain cover resolution function $\mathcal{R}$, an assignment function $g_{\mathcal{R}}$ maps every variable $x$ to some individual concept in $\mathcal{R}(x)$.

Definition 3 (Assignment functions) Given a set of variables $V$, a model $(W, D, I, C)$, and a cover resolution function $\mathcal{R}$, an assignment function $g_{\mathcal{R}}$ is a function that maps every variable $x$ in $V$ to some individual concept in $\mathcal{R}(x)$.

Thus, a variable $x$ is assigned a value in two steps. First, $\mathcal{R}$ determines the conceptual cover that $x$ ranges over, and then $g_{\mathcal{R}}$ maps $x$ to some individual concept in $\mathcal{R}(x)$. Quantification, then, works as follows:

Definition 4 (Quantification under conceptual cover)

- $\llbracket \exists x . \varphi \rrbracket_{M, w, g_{\mathcal{R}}}=1$ iff $\exists c \in \mathcal{R}(x): \llbracket \varphi \rrbracket_{M, w, g_{\mathcal{R}}[x / c]}=1$

- $\llbracket \forall x . \varphi \rrbracket_{M, w, g_{\mathcal{R}}}=1$ iff $\forall c \in \mathcal{R}(x): \llbracket \varphi \rrbracket_{M, w, g_{\mathcal{R}}[x / c]}=1$

\footnotetext{
5 We diverge slightly from Aloni's original terminology and notation here, purely for presentational purposes.
} 
In words, $\exists x . \varphi$ is true in a world $w$ relative to an assignment function $g_{\mathcal{R}}$ iff there is some individual concept $c$ in $\mathcal{R}(x)$, i.e., the conceptual cover that $x$ ranges over according to $\mathcal{R}$, such that $\varphi$ is true in $w$ relative to $g_{\mathcal{R}}[x / c]$, i.e., the assignment that is just like $g_{\mathcal{R}}[x / c]$ except that it assigns the concept $c$ to $x$. And similarly for $\forall x$. $\varphi$. Apart from existential and universal quantification, our analysis of CQs will also make heavy use of the $l$-operator, which is defined as follows.

Definition 5 (The l-operator)

- If there is a unique $c \in \mathcal{R}(x)$ such that $\llbracket \varphi \rrbracket_{M, w, g_{\mathcal{R}}[x / c]}=1$, then:

$$
\llbracket l x . \varphi \rrbracket_{M, w, g_{\mathcal{R}}}=c(w)
$$

- Otherwise, $\llbracket l x . \varphi \rrbracket_{M, w, g_{\mathcal{R}}}$ is undefined.

It should be noted that, even though variables range over the elements of a conceptual cover in this framework, rather than over individuals simpliciter, the denotation of a variable in a certain world is always an individual, not an individual concept.

Definition 6 (The denotation of variables) $\llbracket x \rrbracket_{M, w, g_{\mathcal{R}}}=g_{\mathcal{R}}(x)(w)$

The denotation $\llbracket x \rrbracket_{M, w, g_{\mathcal{R}}}$ of a variable $x$ with respect to a model $M$, a world $w$ and an assignment function $g_{\mathcal{R}}$ is the individual $g_{\mathcal{R}}(x)(w)$, i.e., the value of the concept $g_{\mathcal{R}}(x)$ in world $w$. Thus, variables do not refer to concepts, but to individuals. However, they do refer in a non-rigid way: different individuals can be their value in different worlds.

\subsection{Questions under cover}

Questions are analyzed in terms of their possible exhaustive answers, as in (Groenendijk and Stokhof 1984). However, determining the denotation of a question involves quantification over the elements of a conceptual cover rather than over individuals: 6

Definition 7 (Questions under conceptual cover)

$$
\text { - } \llbracket ? x . \varphi \rrbracket_{M, w, g_{\mathcal{R}}}=\left\{v \mid \forall c \in \mathcal{R}(x): \llbracket \varphi \rrbracket_{M, w, g_{\mathcal{R}}[x / c]}=\llbracket \varphi \rrbracket_{M, v, g_{\mathcal{R}}[x / c]}\right\}
$$

Illustration Consider again the card situation described above. In front of you lie two face-down cards. One is the Ace of Hearts, the other is the Ace of Spades. You don't know which is which. Furthermore, assume that one of the cards is the winning card, but you don't know which. This situation can be modeled as follows (the dot indicates the winning card):

\footnotetext{
6 For simplicity, we only define the semantics of single-constituent questions here (like who called?). See Aloni (2001) for a generalization, which also deals with multi-constituent questions (like who called whom?).
} 


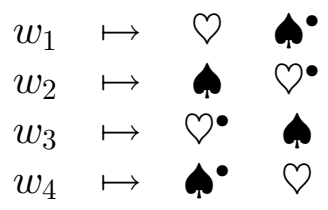

Consider the following interrogative sentence:

(17) a. Which card is the winning card?

b. $? z . z=l x$. WINNING-CARD $(x)$

The evaluation of this sentence depends on the conceptual cover that $z$ ranges over. There are two possible resolutions: under $\mathcal{R}_{1}, z$ ranges over the position cover, while under $\mathcal{R}_{2}, z$ ranges over the suit cover:

$\mathcal{R}_{1}(z)=\{$ the card on the left, the card on the right $\}$

$\mathcal{R}_{2}(z)=\{$ the Ace of Spades, the Ace of Hearts $\}$

The question in (17) partitions the set of worlds in two different ways depending on the assumed cover resolution:

$$
\begin{array}{l|l|}
\hline w_{1} \\
w_{2} \\
\hline w_{3} \\
w_{4}
\end{array} \quad \text { under } \mathcal{R}_{1}: \quad \text { under } \mathcal{R}_{2}: \quad \begin{aligned}
& w_{1} \\
& w_{4} \\
& \hline w_{2} \\
& w_{3} \\
& \hline
\end{aligned}
$$

Under $\mathcal{R}_{1}$, (17) induces a partition which separates worlds where the winning card occupies a different position. Under $\mathcal{R}_{2}$, (17) induces a partition which separates worlds where the winning card is of a different suit. Since different resolutions result in different partitions, the fact that different answers are required in different contexts is accounted for. For instance, (18) counts as an appropriate answer to (17) only under $\mathcal{R}_{2}$ :

(18) The Ace of Spades is the winning card.

\subsection{Knowledge ascription}

In order to translate sentences like John knows which card is the winning card, the language is extended with a knowledge operator $K_{a}$, for every agent $a$ whose epistemic state we would like to describe. The above sentence is then translated as $K_{j}(? z . z=\imath x$. WINNING-CARD $(x))$. A model for the extended language is a quintuple $(W, D, I, C, E)$, where $W, D, I$ and $C$ are as above and $E$ is a function mapping individual-world pairs $(a, w)$ into subsets of $W$. Intuitively, $E(a, w)$ represents the epistemic state of $a$ in $w$. Sentences of the form $K_{a}(? z . \varphi)$ are interpreted as follows:

Definition 8 (Knowledge ascription)

- $\llbracket K_{a}(? z . \varphi) \rrbracket_{M, w, g_{\mathcal{R}}}=1$ iff $E(a, w) \subseteq \llbracket ? z \cdot \varphi \rrbracket_{M, w, g_{\mathcal{R}}}$ 
$K_{a}(? z . \varphi)$ is true in $w$ iff $a$ 's epistemic state is contained in the denotation of ?z. $\varphi$ in $w$.

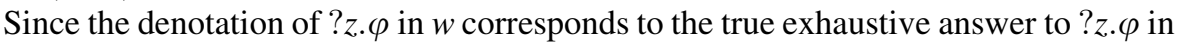
$w, K_{a}(? z . \varphi)$ is true in $w$ iff $a$ 's epistemic state supports the true exhaustive answer to $? z . \varphi$ in $w$.

Illustration Consider again the card situation described above. Suppose now that John knows that the Ace of Spades is the winning card, but he doesn't know whether it is the card on the left or the one on the right. In this situation John's epistemic state corresponds to the set: $\left\{w_{1}, w_{4}\right\}$. Sentence (19) is then correctly predicted to be true under $\mathcal{R}_{2}$, but false under $\mathcal{R}_{1}$.

(19) a. John knows which card is the winning card.

b. $K_{j}(? z . z=l x$.WINNING-CARD(x))

\subsection{Conceptual covers and intensional operators}

In order to understand many of the examples to be discussed below, it is useful to realize that the denotation of $\imath x . \varphi, \exists x . \varphi$, and $\forall x . \varphi$ does not depend on the conceptual cover that is assigned to $x$ by $\mathcal{R}$, as long as $x$ does not occur free in the scope of an intensional operator in $\varphi .^{7}$ This is perhaps easiest to see by considering a simple example. Consider the term $l x . P(x)$, where $P$ is a simple one-place predicate. To determine $\llbracket l x . P(x) \rrbracket_{M, w, g_{\mathcal{R}}}$, we have to check whether there is a unique concept $c \in \mathcal{R}(x)$ such that $\llbracket P(x) \rrbracket_{M, w, g_{\mathcal{R}}[x / c]}=1$. If we can find such a unique concept $c$, then the value of $\llbracket l x . P(x) \rrbracket_{M, w, g_{\mathcal{R}}}$ is $c(w)$. But since $\mathcal{R}(x)$ is a conceptual cover and the individual concepts in a conceptual cover are all instantiated by a unique individual in every world, we know that there is a unique concept $c \in \mathcal{R}(x)$ such that $\llbracket P(x) \rrbracket_{M, w, g_{\mathcal{R}}[x / c]}=1$ just in case the extension of $P$ in $w$ consists of a unique individual $d \in D$. Moreover, in this case we have that $\llbracket l x . P(x) \rrbracket_{M, w, g_{\mathcal{R}}}=c(w)=d$. This means that, to determine $\llbracket l x . P(x) \rrbracket_{M, w, g_{\mathcal{R}}}$, we do not really need to know anything about $\mathcal{R}$. We just need to look at the extension of $P$ in $w$, and check whether this extension consists of a unique individual $d$. If so, $\llbracket l x . P(x) \rrbracket_{M, w, g_{\mathcal{R}}}=d$. Otherwise, $\llbracket l x . P(x) \rrbracket_{M, w, g_{\mathcal{R}}}$ is undefined.

This reasoning also goes through if instead of $\iota x . P(x)$ we consider $\exists x . P(x)$ or $\forall x . P(x)$, or if instead of $P$ we take an arbitrarily complex predicate $\varphi$, as long as $x$ does not occur free in the scope of an intensional operator in $\varphi$. Below we will see many examples where $x$ does occur in the scope of an intensional operator in $\varphi$ (see for instance example (24) in the next subsection where $x$ occurs free in the scope of a question operator). In these cases, it matters which conceptual cover $x$ ranges over. But we will also see many examples where $x$ does not occur free in the scope of an intensional operator. When considering such examples, always keep in mind that it does not really matter which conceptual cover $x$ ranges over.

\footnotetext{
7 An operator $\Sigma$ is called intensional if and only if the denotation of an expression $\Sigma \varphi$ in a world $w$ depends on the denotation of $\varphi$ in worlds other than $w$. In our formal language, the only intensional operators are the question operator and the knowledge operator.
} 


\subsection{Concealed questions under cover}

Aloni (2008) applies the above analysis of questions and knowledge ascription to the domain of CQs. She assumes that the interpretation of CQs involves a typeshifting operator $\uparrow_{z}$ which transforms an entity denoting expression $\alpha$ into the identity question $? z \cdot z=\alpha$ (which $z$ is $\alpha$ ?), where $z$ ranges over some contextually determined conceptual cover.

$$
\uparrow_{z} \alpha={ }_{\text {def }} ? z \cdot z=\alpha
$$

Illustrations First consider a 'plain' definite CQ:

(21) a. John knows the capital of Italy.

b. $\quad K_{j}\left(\uparrow_{z} l x . P x\right) \quad\left(=K_{j}(? z . z=\imath x . P x)\right)$

When a proposition embedding verb like know applies to an entity denoting expression like the capital of Italy, the type-shifting operator $\uparrow_{z}$ must apply to avoid a type mismatch. The resulting sentence is then interpreted according to the analysis of knowledge ascription given in the previous section.

$$
\llbracket K_{j}(? z . z=\imath x . P x) \rrbracket_{M, w, g_{R}}=1 \text { iff } E(j, w) \subseteq \llbracket ? z . z=\imath x . P x \rrbracket_{M, w, g_{R}}
$$

The intended reading is obtained if $x$ and $z$ are both taken to range over the naming cover: ${ }^{8}$

$$
x, z \rightarrow\{\text { Berlin, Rome, Paris, ... }
$$

Under this resolution the embedded question $? z \cdot z=\imath x \cdot P x$ denotes in $w$ the proposition that Rome is the capital of Italy, if Rome is indeed the capital of Italy in $w$. Sentence (21) then is true in $w$ iff John's epistemic state in $w$ supports this proposition.

Example (24) illustrates Aloni's analysis of quantified CQs:
a. John knows every European capital.
b. $\forall x$. (EUROPEAN-CAPiTAL $\left.(x) \rightarrow K_{j}\left(\uparrow_{z} x\right)\right)$

The most natural cover resolution for $x$ and $z$ here is the following:

$$
\begin{aligned}
& \text { a. } \quad x \rightarrow\{\text { the capital of Germany, the capital of Italy }, \ldots\} \\
& \text { b. } \quad z \rightarrow\{\text { Berlin, Rome }, \ldots\}
\end{aligned}
$$

The sentence is then predicted to be true iff for each European country John can name the capital of that country. This captures the specificational reading of the sentence. Notice that contrary to the previous example, the quantified case crucially

\footnotetext{
8 Notice that, as explained in Section 3.5 operators, it does not really matter which cover $x$ is taken to range over, since $x$ does not occur free in an intensional context.
} 
requires that $x$ and $z$ range over two different covers, otherwise the question $? z \cdot z=x$ would be trivialized (i.e., it would denote a tautology in every world, relative to any assignment function).

Finally, we turn to Heim's CCQ ambiguity. As we mentioned in the introduction, Heim (1979) observed that sentences like (26) have the two readings paraphrased in (27) and (28).

(26) John knows the capital that Fred knows.

(27) Reading A:

There is exactly one country $x$ such that Fred can name $x$ 's capital; and John can name $x$ 's capital as well.

(28) Reading B:

John knows which country $x$ is such that Fred can name $x$ 's capital (although John may be unable to name $x$ 's capital himself).

Aloni analyzes Heim's ambiguity as a de relde dicto ambiguity:

(29) John knows the capital that Fred knows.

$$
\begin{array}{ll}
\exists x \cdot\left(x=l y \cdot\left(\operatorname{CaPITAL}(y) \wedge K_{f}\left(\uparrow_{z_{1}} y\right)\right) \wedge K_{j}\left(\uparrow_{z_{2}} x\right)\right) & \text { [Reading A] } \\
K_{j}\left(\uparrow_{z_{3}} l y \cdot\left(\operatorname{CAPITAL}(y) \wedge K_{f}\left(\uparrow_{z_{4}} y\right)\right)\right) & \text { [Reading B] }
\end{array}
$$

The intended readings are captured by assuming the following cover resolution for the variables:

(30) a. $x, y, z_{3} \rightarrow\{$ the capital of Germany, the capital of Italy, ...

b. $z_{1}, z_{2}, z_{4} \rightarrow\{$ Berlin, Rome, ...

On this resolution, Reading A says that there is a unique capital which Fred can identify by name, and that John can identify that capital by name as well. On Reading B, John can identify 'the capital that Fred knows' with one of the individual concepts in the conceptual cover associated with $z_{3}$. That is, there is some country $x$ such that 'the capital that Fred knows' denotes the same city as 'the capital of $x$ ' in all worlds in John's epistemic state. ${ }^{9}$

\subsection{Some outstanding issues}

Aloni's account captures some of the basic semantic aspects of CQs. However, it leaves several issues unaddressed. Below we briefly discuss five such issues.

Predicational readings of quantified CQs. As noted above, quantified CQs like:

(31) John knows every phone number.

\footnotetext{
9 See Aloni (2008) for a more detailed description of how these readings are obtained.
} 
are ambiguous between a specificational reading:

(32) John knows that Ann's number is 503, that Bill's number is 431, etc.

and a predicational reading:

(33) John knows of every phone number whether it is a phone number.

As shown in Section 3.6, Aloni's theory accounts for the specificational reading. But it has no way of accounting for the predicational reading.

Ambiguity of quantified CCQs. Recall that Aloni analyzes the A/B ambiguity of definite CQs such as:

(34) John knows the capital that Fred knows.

as a de relde dicto ambiguity. On the other hand, her account of quantified CQs assumes a de re representation. That is, quantified CCQs such as (35) must be represented de re.

(35) John knows every capital that Fred knows.

But this means that the A/B ambiguity of quantified CCQs cannot be derived as a de relde dicto ambiguity. ${ }^{10}$

Greenberg's observation. The contrast between (36) and (37), first noted by Greenberg (1977), constitutes another open issue for Aloni's account. ${ }^{11}$

(36) John found out the murderer of Smith.

(37) John found out who the murderer of Smith was.

Sentence (36) contains a CQ, whereas (37) contains a full interrogative clause. Greenberg observed that there is a subtle difference in meaning between the two sentences: (36) necessarily entails that John solved the question of who murdered Smith (direct reading); (37) does not necessarily have this entailment - it may be used to report, for example, that John found out that his gardener was a much sought-after criminal known as The Strangler even if John did not find out that the guy actually murdered Smith (indirect reading). This contrast clearly stands in need of an explanation, especially on an approach that assimilates CQs to interrogative complement clauses.

10 Aloni's theory does provide for an alternative strategy to derive the A/B ambiguity, but only under certain rather unnatural assumptions about cover resolution (see Roelofsen and Aloni 2008, for more discussion of this issue).

11 As Frana (2010a) reports, most English speakers tend to dislike CQs with find out. However, the contrast can be reproduced by replacing find out with discover. 
Basic and derived covers. By definition, a conceptual cover is a set of individual concepts such that every concept picks out exactly one individual in every world. There are many examples of CQs which seem to require quantification over a domain of individual concepts that does not necessarily have this special property. Consider the following example:

(38) John knows the price that Fred knows.

Heim's reading B of (38) says that John knows which price Fred knows (e.g., the price of milk, the price of butter, or the price of bread). This reading involves quantification over the following domain of individual concepts:

$\{$ the price of milk, the price of butter, the price of bread, ...

Now, it is possible, of course, that the price of butter and the price of milk coincide in some world, which would mean that not every individual is picked out by a unique concept in that world. Thus, the required domain of quantification is not necessarily a conceptual cover. ${ }^{12}$

Notice that this problem does not arise for our original example, (8), just because it happens to be impossible for two countries to have the same capital city. The problem does arise, however, for analogous examples involving temperatures, scores, colors, dates of birth, etc.

To overcome this problem we will make a distinction between basic covers and derived covers. Basic covers are conceptual covers that satisfy the original requirement that in every world, every individual instantiates exactly one concept. Given a basic cover $C$ and a function $f_{\langle s,\langle e, e\rangle\rangle}$, the derived cover based on $C$ and $f$ is defined as follows:

$$
\left\{c \mid \exists c^{\prime} \in C \cdot \forall w . c(w)=f(w)\left(c^{\prime}(w)\right)\right\}
$$

For example, $\{$ the capital of Italy, the capital of Germany, ... $\}$ is a derived cover based on $\{$ Italy, Germany, ... $\}$ and the capital-of function. We will assume that domains of quantification may be derived covers, as well as basic covers, and that functional nouns like price and capital can make derived covers particularly salient (the connection between functional nouns and CQs has received much attention in the literature, see especially Nathan (2006) and Frana (2010a)). ${ }^{13}$

CQ distribution. A final issue that Aloni's proposal leaves unaddressed is the distribution of CQs. In particular, since CQs are semantically treated as questions on this approach, an explanation is needed of the fact that there are verbs selecting for full interrogative clauses, but not for CQs:

\footnotetext{
12 A closely related observation has been made by Schwager (2007a).

13 Although the notion of derived covers defined here serves our present purposes, it is not without potential pitfalls. Appendix A.2 provides some further discussion of this issue.
} 
(41) a. John wonders/inquires what the capital of Italy is.

b. *John wonders/inquires the capital of Italy.

Indeed, examples like (41) have been presented by Nathan (2006) and Frana (2006, 2010a) as a general argument against approaches that treat CQs as questions. In our view, these examples do not really constitute such an argument. They just show that there are certain differences between CQs and full-fledged interrogative clauses that certain embedding verbs are sensitive to. To illustrate this point, consider the following contrast, first noted by Karttunen (1977b):

(42) a. I doubt whether they serve breakfast.

b. *I doubt what they serve for breakfast.

We cannot conclude from this contrast that the two embedded clauses must differ in semantic type. We can only conclude that there must be a certain difference between the two clauses that the verb doubt is sensitive to. Similarly, we can conclude from the contrast in (41) that there must be a certain difference between CQs and full interrogative complement clauses that the verbs wonder and inquire are sensitive to. This could be a difference in semantic type, but that is not necessarily the case. That said, the contrast in (41) does of course stand in need of an explanation, and Aloni (2008) does not provide such an explanation.

In the next section we will develop a detailed account of the interpretation of CQs, addressing the first three issues listed above. The distribution of CQs will not be the main focus of the paper, but in Appendix A.1 we do show that it is in principle possible - contrary to what Nathan (2006) and Frana (2010a) may be taken to suggest - to develop a semantic account of the distributional facts that is compatible with our theory of CQ interpretation.

\section{Interpreting concealed questions}

\subsection{Basic proposal}

We take as our point of departure the specificational/predicational ambiguity of quantified CQs. As pointed out above, Aloni's theory does not account for this ambiguity. ${ }^{14}$ What is it that makes this case so challenging? Consider again the standard example:

John knows every phone number.

Let us assume (44) as a representation of the truth-conditional meaning of (43), without yet fixing the exact definition of the type-shifting operator $\uparrow$.

\footnotetext{
${ }^{14}$ When this paper was submitted for publication (in November 2009) the specificational/predicational ambiguity of quantified CQs was problematic for all existing theories of CQs. In the meantime, Frana (2010a) and Romero (2010) have proposed an account of the ambiguity that differs from the one to be proposed here. A detailed comparison must be left for another occasion.
} 


$$
\forall x .\left(\operatorname{PHONENUMBER}(x) \rightarrow K_{j}(\uparrow x)\right)
$$

Now let us just see how $\uparrow$ should be defined to get the facts right. In order to capture the specificational reading, we need:

$$
\uparrow x \rightsquigarrow ? z . z=x
$$

with:

- $x \rightarrow\{$ Ann's phone number, Bill's phone number, ... $\}$

- $z \rightarrow\{5403,5431, \ldots\}$

In order to get the predicational reading, we want:

$$
\uparrow x \rightsquigarrow ? \operatorname{PHONENUMBER}(x)
$$

with:

- $x \rightarrow\{5403,5431, \ldots\}$

To capture this flexibility, we will assume that $\uparrow$ transforms an entity-denoting expression $\alpha$ into the question ?z.P( $\alpha)$.

$$
\uparrow_{(z, P)} \alpha={ }_{\mathrm{def}} ? z \cdot P(\alpha)
$$

The type-shift has two pragmatic parameters: $z$ ranges over some contextually determined conceptual cover and $P$ is a contextually determined property. We assume that by default $P$ is resolved to the property of being identical to $z$, i.e., to the "identity property" $\lambda y . y=z$; or to the property expressed by the CQ noun phrase. In the latter case, the cover resolution of $z$ becomes irrelevant. Indeed, if $z$ does not occur free in $P$ and $\alpha$, then ?z.P( $\alpha)$ is equivalent to ?P( $\alpha)$, and we will avoid reference to $z$ altogether. Finally, we assume that $z$ by default ranges over a naming cover, a rigid cover (in case the individuals in the relevant domain can be identified by ostension, as in the card example discussion in Section 2), or a derived cover based on a functional CQ noun (if such a cover is salient in the given context).

Thus, (43) is now analyzed as:

$$
\forall x .\left(\operatorname{PHONENUMBER}(x) \rightarrow K_{j}(? z . P(x))\right)
$$

The specificational reading results from the following resolution:

- $x \rightarrow\{$ Ann's phone number, Bill's phone number, ...

- $z \rightarrow\{5403,5431, \ldots\}$

- $P \rightarrow \lambda y \cdot y=z$

which yields:

$$
\forall x .\left(\operatorname{PHONENUMBER}(x) \rightarrow K_{j}(? z . z=x)\right)
$$


The predicational reading results from the following resolution: ${ }^{15}$

- $x \rightarrow\{5403,5431, \ldots\}$

- $P \rightarrow$ PHONENUMBER

which yields:

\section{$\forall x .\left(\operatorname{PHONENUMber}(x) \rightarrow K_{j}(? \operatorname{PhONENUMBER}(x))\right)$}

In the first case $P$ is resolved to the "identity property", in the second case to the property expressed by the CQ noun phrase. The resolution of $z$ is only relevant in the first case. Notice that, at least for this example, the proposed account does not overgenerate. The only available covers are the naming cover $\{5403,5431, \ldots\}$ and the derived cover $\{$ Ann's phone number, Bill's phone number, ... $\}$. The only salient properties are the identity property and PHONENUMBER. As a result, any resolution of $x$, $z$ and $P$ will yield either the specificational or the predicational reading described above.

\subsection{CCQs}

Let us now consider the case of CCQs. So far we have assumed that CCQs are twoway ambiguous between the A and B readings that Heim (1979) identified. The theory proposed here, however, predicts that there are several additional readings. And upon closer examination these readings are indeed available. ${ }^{16}$ To illustrate this, let us consider the most general and most challenging case: quantified CCQs (the theory deals with definite and indefinite CCQs in an analogous way). Consider our initial example:

(51) John knows every capital that Fred knows.

and its analysis:

$$
\forall x \cdot\left(\left(\operatorname{Capital}(x) \wedge K_{f}\left(? z_{1} \cdot P_{1}(x)\right)\right) \rightarrow K_{j}\left(? z_{2} \cdot P_{2}(x)\right)\right)
$$

It will be useful to make a distinction between two general types of readings. On the first type of reading, (51) says something about John's knowledge in contrast/ comparison with Fred's knowledge. On the second type of reading, (51) is concerned with John's knowledge about Fred's knowledge. We will refer to readings of the first type as A readings, and to those of the second type as B readings. Notice that on this terminology, the two readings originally described by Heim (1979) are

\footnotetext{
15 The cover resolution of $z$ will be left unspecified whenever it is irrelevant, i.e., whenever $P$ is not resolved to the identity property.

16 Independently from our work, Heim (2009) herself also recently pointed out the existence of additional readings for CCQs. In particular, she discussed what we will call below the predicational A and B readings (she called them individual-based A and B readings) and presented an account of these readings, which she attributed to Ilaria Frana (later published in Frana, 2010a, pp. 140-183). However, we will see that besides the 'original' A and B readings, and the predicational ones, there are even more.
} 
indeed A- and B-type readings, respectively. However, there are several additional A- and B-type readings as well. Let us first consider the A-type readings in more detail.

There are three different A-type readings that quite naturally arise. First, consider a context where John and Fred are given a list of cities, and are asked which of these cities are capitals. In this context, $(51)$ can be taken to mean that for every city $x$ such that Fred knows that $x$ is a capital city, John also knows that $x$ is a capital city (a predicational reading).

Second, consider a context where John and Fred are given a list of cities, and are asked to specify the countries that these cities are the capitals of. In this context, (51) can be taken to mean that for every capital $x$ such that Fred can specify the country that $x$ is the capital of, John can also specify the country that $x$ is the capital of (a specificational reading).

Finally, consider a context where John and Fred are given a list of countries, and are asked to specify the capitals of these countries. In this context, (51) can be taken to mean that for every country $y$ such that Fred can specify $y$ 's capital, John can also specify $y$ 's capital (another specificational reading).

These readings correspond to the following resolutions: ${ }^{17}$

\section{Predicational A reading:}

- $x \rightarrow\{$ Rome, Berlin, Paris, ... $\}$

- $P_{1}, P_{2} \rightarrow$ CAPITAL

- Given this resolution, (52) reduces to:

$$
\forall x \text {. }\left(\left(\operatorname{CAPITAL}(x) \wedge K_{f}(? \mathrm{CAPITAL}(x))\right) \rightarrow K_{j}(\text { ?CAPITAL }(x))\right)
$$

First specificational A reading:

[capitals given, countries asked]

- $x \rightarrow\{$ Rome, Berlin, Paris, ...

- $z_{1}, z_{2} \rightarrow\{$ the capital of Italy, the capital of Germany, ...

- $P_{1} \rightarrow \lambda y \cdot y=z_{1}$

- $P_{2} \rightarrow \lambda y \cdot y=z_{2}$

- Given this resolution, (52) reduces to:

$$
\forall x .\left(\left(\operatorname{capital}(x) \wedge K_{f}\left(? z_{1} \cdot x=z_{1}\right)\right) \rightarrow K_{j}\left(? z_{2} \cdot x=z_{2}\right)\right)
$$

Second specificational A reading:

[countries given, capitals asked]

- $x \rightarrow\{$ the capital of Italy, the capital of Germany, ...

- $z_{1}, z_{2} \rightarrow\{$ Rome, Berlin, Paris, ...\}

- $P_{1} \rightarrow \lambda y \cdot y=z_{1}$

- $P_{2} \rightarrow \lambda y \cdot y=z_{2}$

17 Given our semantic treatment of knowledge ascription, the two specificational readings turn out to be truth-conditionally equivalent. However, a more sophisticated treatment of knowledge ascription should be able to tease these two readings apart. To see this, suppose that neither John nor Fred is able to specify the capital of any country other than France. Additionally, Fred knows that Italy is the only country in the world whose capital starts with an ' $\mathrm{R}$ ' and ends with an ' $\mathrm{e}$ '. John doesn't know this. Then, intuitively, John knows every capital that Fred knows in the [countries given, capitals asked] scenario, but not in the [capitals given, countries asked] scenario, since Fred can tell us which country Rome is the capital of, while John can't. 
- Given this resolution, (52) reduces to:

$\forall x .\left(\left(\operatorname{Capital}(x) \wedge K_{f}\left(? z_{1} \cdot x=z_{1}\right)\right) \rightarrow K_{j}\left(? z_{2} \cdot x=z_{2}\right)\right)$

Notice that for the predicational reading, $P_{1}$ and $P_{2}$ are both resolved to the property expressed by the CQ noun phrase, while for the two specificational readings $P_{1}$ and $P_{2}$ are both resolved to the identity property, and $z_{1}$ and $z_{2}$ are taken to range over the same cover. This 'parallelism effect' is expected since (51) is interpreted here as a contrastive statement (the parallelism effect of contrast on resolution is familiar from the literature on ellipsis, cf. Rooth 1992; Heim 1997; Fox 1999; Roelofsen 2008).

Now let us consider the B-type readings, which report John's knowledge about Fred's knowledge. Again, three readings quite naturally arise.

First, consider a context in which Fred is given a list of cities, and is asked which of these cities are capitals. John is asked to predict how Fred will respond. In this context, (51) can be taken to mean that for every capital $x$ such that Fred knows that $x$ is a capital, John knows that Fred knows that $x$ is a capital (a predicational reading).

Second, consider a context in which Fred is given a list of capitals, and is asked to specify which countries these are the capitals of. Again, John is asked to predict how Fred will respond. In this context, (51) can be taken to mean that for every capital $x$ such that Fred can specify the country that $x$ is the capital of, John knows that $x$ is a capital such that Fred can specify the country that $x$ is the capital of. We will call this a 'mixed' reading because it reports that John has 'predicational knowledge' about a range of concepts that are characterized in terms of Fred's 'specificational knowledge'.

Finally, consider a context in which Fred is given a list of countries, and is asked to specify the capitals of these countries. Again, John is asked to predict how Fred will respond. In this context, (51) can be taken to mean that for every country $y$ such that Fred can specify $y$ 's capital, John knows that $y$ is a country such that Fred can specify its capital (another mixed reading). These readings correspond to the following resolutions:

Predicational B reading:

- $x \rightarrow\{$ Rome, Berlin, Paris, ...\}

- $P_{1} \rightarrow$ CAPITAL

- $P_{2} \rightarrow \lambda x$.CApital $(x) \wedge K_{f}\left(? z_{1} \cdot P_{1}(x)\right)$

- Given this resolution, (52) reduces to: $\forall x .\left(\left(\operatorname{Capital}(x) \wedge K_{f}(? \operatorname{CaPital}(x))\right) \rightarrow K_{j}\left(?\left(\operatorname{CaPiTAL}(x) \wedge K_{f}(? \operatorname{CaPITAL}(x))\right)\right)\right)$

First mixed B reading: [capitals given, countries asked]

- $x \rightarrow\{$ Rome, Berlin, Paris, ...\}

- $z_{1} \rightarrow\{$ the capital of Italy, the capital of France,...\}

- $P_{1} \rightarrow \lambda y \cdot y=z_{1}$

(specificational)

- $P_{2} \rightarrow \lambda x$.CAPITAL $(x) \wedge K_{f}\left(? z_{1} \cdot P_{1}(x)\right)$

(predicational)

- Given this resolution, (52) reduces to: $\forall x .\left(\left(\operatorname{Capital}(x) \wedge K_{f}\left(? z_{1} \cdot x=z_{1}\right)\right) \rightarrow K_{j}\left(?\left(\operatorname{CAPITAL}(x) \wedge K_{f}\left(? z_{1} \cdot x=z_{1}\right)\right)\right)\right)$ 
Second mixed B reading:

[countries given, capitals asked]

- $x \rightarrow\{$ the capital of Italy, the capital of France, ... $\}$

- $z_{1} \rightarrow\{$ Rome, Berlin, Paris, ... $\}$

- $P_{1} \rightarrow \lambda y \cdot y=z_{1}$

- $P_{2} \rightarrow \lambda x$.CAPITAL $(x) \wedge K_{f}\left(? z_{1} \cdot P_{1}(x)\right)$

(specificational)

- Given this resolution, (52) reduces to:

(predicational)

$\forall x .\left(\left(\operatorname{CaPiTAL}(x) \wedge K_{f}\left(? z_{1} \cdot x=z_{1}\right)\right) \rightarrow K_{j}\left(?\left(\operatorname{CAPITAL}(x) \wedge K_{f}\left(? z_{1} \cdot x=z_{1}\right)\right)\right)\right)$

There are two things to note here. First, the fact that mixed readings arise in this case is no surprise. As alluded to above, the absence of mixed A readings is due to the fact that $\mathrm{A}$ readings are contrastive in nature. $\mathrm{B}$ readings are not contrastive, so mixed readings are in principle just as likely to arise here as purely specificational and purely predicational readings.

Second, notice that all the described $\mathrm{B}$ readings involve resolution of $P_{2}$ to the property $\lambda x$.CAPITAL $(x) \wedge K_{f}\left(? z_{1} \cdot P_{1}(x)\right)$. This is not accidental: it reflects the fact that these readings all concern John's knowledge about Fred's knowledge. This also explains why we do not get even more B readings: once the resolution of $P_{2}$ is fixed, the only freedom that remains is in resolving $P_{1}$ and the cover indices. If $P_{1}$ is resolved to CAPITAL, then any default cover resolution either yields the predicational B reading described above $\left(x \rightarrow\right.$ naming), or a trivial meaning ( $x \rightarrow$ capitals). If $P_{1}$ is resolved to the identity property, then any default cover resolution either yields one of the mixed $\mathrm{B}$ readings described above, or again a trivial meaning. Assuming that trivial meanings are generally avoided, it is predicted that, as long as we confine ourselves to default resolutions, the three B readings described above are the only ones that arise.

Thus, the complete range of CCQ readings is accounted for in a straightforward and perspicuous way, and as long as we stick to default resolutions the proposed theory does not overgenerate.

\subsection{Further widening the empirical domain}

Now let us turn to some further challenging cases. In particular, we will consider Greenberg's observation, which was already mentioned in Section 3.7, and several related facts. Some of these will speak in favor of the proposed account, but others will reveal an issue of potential overgeneration. This will lead us to a more in-depth analysis of the constraints that play a role in the pragmatic resolution process.

Greenberg's observation. Recall Greenberg's (1977) observation: ${ }^{18}$

John found out the murderer of Smith.

(54) John found out who the murderer of Smith was.

\footnotetext{
18 As mentioned before, most English speakers tend to dislike CQs with find out, but the contrast can be reproduced by replacing find out with discover (Frana 2010a).
} 
Sentence (53) contains a CQ, whereas (54) contains a full interrogative clause. Greenberg observed that there is a subtle difference in meaning between the two: (53) necessarily entails that John solved the question of who murdered Smith (direct reading); (54) does not necessarily have this entailment-it may be used to report, for example, that John found out that his gardener was a much sought-after criminal known as The Strangler even if John did not find out that the guy actually murdered Smith (indirect reading). This observation has given rise to the generalization, which we will refer to as Greenberg's generalization, that CQs only allow for direct readings, while wh-complements allow both for direct and for indirect readings. We will show, however, that several exceptions to this generalization can be found.

First exception: Arequipa. Tomas is confronted with the following list of South American cities:

Caracas, Montevideo, Lima, Porto Alegre, Quito, Arequipa.

He is challenged to say which of these cities are capitals and which are not. His wife Tereza reports:

He only knew the city we visited on our honeymoon last year.

On its most natural reading, this sentence conveys that Tomas only knew of the city that he and Tereza visited on their honeymoon last year, say Arequipa, whether or not it was a capital city. ${ }^{19}$ Crucially, Tereza does not report that Tomas only knew that Arequipa was the city that they visited on their honeymoon last year. ${ }^{20}$

Second exception: the Obamas. Michelle Obama tells her daughters, Malia Ann and Sasha:

(57) Today I went to visit a primary school in the neighborhood. At some point one of the children-I think his name was Billy-was asked to name the presidents of some American countries. But, poor kid, he only knew your father.

\footnotetext{
${ }^{19}$ Besides the described CQ reading, this sentence also has an acquaintance reading. An anonymous reviewer suggested that this acquaintance reading may in fact be the only reading available for (56). However, in languages like Italian and Dutch, where epistemic know and acquaintance know are lexically distinct, direct translations of (56) with the epistemic verbs sapere and weten, given below, clearly exhibit the relevant $\mathrm{CQ}$ reading.

(i) a. Ha saputo solo la città che abbiamo visitato l'anno scorso in viaggio di nozze.

b. Hij wist alleen de stad die wij vorig jaar op onze huwelijksreis bezocht hebben.

20 This example also shows that $P(\alpha)$ should be within the scope of the question operator (contra Heim (1979) and Frana (2006)): Tereza reports that Tomas knew whether the city they visited on their honeymoon was a capital, not necessarily that it was a capital.
} 
On its most natural reading, the underlined sentence says that Billy only knew that Barack Obama was the president of the United States. Crucially it does not entail that he knew that Barack Obama was Malia Ann's and Sasha's father.

Last exception. We have already seen another phenomenon which is in conflict with Greenberg's generalization: A-type readings of CCQs. Consider our initial example of a definite CCQ:

John knows the capital that Fred knows.

Taking Greenberg's generalization at face value, we should expect that the sentence entails that John knows of the capital that Fred knows that it is the capital that Fred knows. But we have already seen that this is not necessarily so. A-type readings of (58) say that John and Fred know the same capital, but do not necessarily entail that John knows anything about Fred.

These exceptions are hard, if not impossible, to explain on previous accounts of Greenberg's generalization (Nathan 2006; Frana 2006, 2010b). The theory proposed here is flexible enough to deal with them. However, pragmatic accounts always run the risk of overgeneration. Greenberg's original observation, as well as the following example-due to Maribel Romero-clearly show that the pragmatic resolution process must be carefully constrained.

Romero's observation. Lucia just learned her first capital in Kindergarten: she learned that the capital of France is Paris. When her mother picks her up and hears the news from the care-takers, she decides to play a guessing game on her husband Ben in the evening: he will have to find out which capital Lucia learned that day. But incidentally Ben talks to one of the Kindergarten care-takers on the phone later that day and also hears the news. This means that Lucia's mother won't be able to play her guessing game anymore, because:

(59) a. Ben (already) knows the capital that Lucia knows.

b. \#Lucia knows the capital that Ben (already) knows.

Sentence (59b) does not convey the intended message in this situation. On our account, however, it is represented as in (60), and it is not hard to find a possible resolution such that (60) indeed entails that 'Ben already knows the capital that Lucia knows'.

$$
\exists x_{1} \cdot\left(x_{1}=\imath x_{2} \cdot\left(\operatorname{CAPITAL}\left(x_{2}\right) \wedge K_{b}\left(? z_{1} \cdot P_{1}\left(x_{2}\right)\right)\right) \wedge K_{l}\left(? z_{2} . P_{2}\left(x_{1}\right)\right)\right)
$$

$\underline{\text { Problematic resolution: }}$

- $x_{1}, x_{2} \rightarrow\{$ the capital of Italy, the capital of France, ...

- $z_{2} \rightarrow\{$ Rome, Berlin, Paris, ...\}

- $P_{1} \rightarrow \lambda y$.CAPITAL $(y) \wedge K_{l}\left(? z_{2} . P_{2}(y)\right)$

- $P_{2} \rightarrow \lambda y \cdot y=z_{2}$ 
So, on the one hand, we need a flexible, context-sensitive account to deal with the 'exceptional' cases mentioned above, but on the other hand, the resolution process needs to be suitably constrained. The following section discusses some factors that we take to play a crucial role in this process.

\subsection{Constraints on resolution}

On the proposed account, the interpretation of a CQ involves a type shift $\uparrow_{(z, P)}$, where $P$ and the domain that $z$ ranges over are contextually determined. As mentioned earlier, we assume that there are certain default choices for $P$ and the domain that $z$ ranges over. In particular, we assume that $P$ is by default resolved to the property of being identical to $z$ or to the property expressed by the CQ noun phrase, and that $z$ by default ranges over the naming cover, the rigid cover (if the individuals in the relevant domain can be identified by ostension), or a derived cover based on a functional CQ noun (if such a cover is salient in the given context). But when exactly does an interpreter deviate from these default resolutions?

Our proposal is that deviation from the default properties/covers is possible, but costly, and only justified if it is needed in order to comply with Gricean principles of conversation. More precisely, following Aloni (2001), we assume that resolution to a non-default salient property/cover is licensed only if it is needed in order to avoid trivial, contradictory or irrelevant meanings, and only if the obtained interpretation could not have been expressed by a more perspicuous/effective form. In sum:

\section{Default resolutions for $P$ and the domain of $z$ :}

- $P$ is by default resolved to:

- the property of being identical to $z$;

- the property expressed by the CQ noun phrase.

- $z$ is by default taken to range over:

- the naming cover;

- the rigid cover (if the individuals in the relevant domain can be identified by ostension);

- a derived cover based on a functional CQ noun (if salient).

\section{Deviation from default resolutions is licensed:}

- only if necessary to avoid contradictory/trivial/irrelevant meanings; [quality, quantity, relevance]

- and only if the meaning obtained by shifting to a non-default resolution could not have been expressed by a more perspicuous/effective form.

[manner as blocking]

Below we will illustrate how these principles account for Greenberg's and Romero's observations, as well as the other cases discussed in Section 4.3.

Greenberg's concealed question example. Greenberg's CQ example, repeated in (61), has two possible representations, given in (61a) and (61b): 
(61) John found out the murderer of Smith.

a. $\quad F_{j}\left(\uparrow_{(z, P)} l x\right.$. MURDERER-OF-SMITH $\left.(x)\right)$

b. $\quad \exists y \cdot\left(y=\imath x\right.$.MURDERER-OF-SMith $\left.(x) \wedge F_{j}\left(\uparrow_{(z, P)} y\right)\right)$

In a neutral context, the possible resolutions for $y, z$ and $P$ are the following:
a. Covers: naming
b. Properties: identity, MURDERER-OF-SMITH

Consider first the de dicto representation in (61a). In a neutral context, the predicted resolution for $P$ is the identity property-the other salient property, MURDERER-OF-SMITH, yields a trivial meaning. The only possible cover for $z$ is the naming cover - there are no other salient covers. This gives us a 'direct reading' of (61), which entails that John solved the question of who murdered Smith.

Now consider the de re representation in $(61 \mathrm{~b})$. In this case, the predicted resolution for $P$ is the property MURDERER-OF-SMITH rather than the identity property, which would yield a trivial meaning. The variable $y$ must range over the naming cover, the only salient cover. This, again, gives us a direct reading of (61), entailing that John solved the question of who murdered Smith.

Hence, in a neutral context the resolution process is constrained in such a way that (61) can only be assigned a direct reading, in agreement with Greenberg's observation.

\section{Summary of predicted resolutions:}

- For (61a): $P \rightarrow$ Id $\& z \rightarrow$ naming

'John learned to identify the murderer of Smith by name'

- For (61b): $P \rightarrow$ MURD-OF-S \& $y, z \rightarrow$ naming $\quad[P \rightarrow \mathrm{Id} \Rightarrow$ trivial $]$ 'Of the name of the murderer of Smith John found out whether it was the name of the murderer of Smith'

Greenberg's non-concealed question example. Consider now the non-concealed question example from Greenberg, repeated in (63), and its two possible representations:

(63) John found out who the murderer of Smith was.

a. $\quad F_{j}(? z . z=\imath x$. MURDERER-OF-SMITH $(x))$

b. $\exists y \cdot\left(y=\imath x \cdot\right.$ MURDERER-OF-SMITH $\left.(x) \wedge F_{j}(? z . z=y)\right)$

Consider first the de dicto representation in (63a). In a neutral context, the only possible cover for $z$ is the naming cover-as in the case of (61a). This gives us again a 'direct reading', which entails that John solved the question of who murdered Smith.

Now consider the de re representation in (63b). This case is crucially different from that of (61b). There we predicted a predicational reading which here, given the different logical form of the sentence, is not possible. The only way to avoid a trivial meaning for the embedded identity question in (63b) is to assign two different 
covers to $y$ and $z$. These could be naming and the derived murderers cover (if salient) or, for example, naming and a cover like $A=\{$ the much sought-after criminal known as The Strangler, the new criminal on the block, ... (if salient). In the latter case we would obtain an indirect reading.

Crucially, even in a context where cover $A$ is salient, the de re representation of Greenberg's CQ example, (61b), does not yield an indirect reading. This is because, in the case of (61b), a direct reading is obtained by means of a default resolution $(P \rightarrow$ MURDERER-OF-SMith $\& z \rightarrow$ naming). Since this reading is consistent and nontrivial, a non-default resolution is not licensed. By contrast, the de re representation of Greenberg's non-concealed question example, (63b), yields a trivial meaning unless we allow for a non-default resolution. This licenses resolution to a nondefault cover like $\mathrm{A}$, which gives rise to an indirect reading.

\section{Summary of predicted resolutions:}

- For (63a): default resolution: $z \rightarrow$ naming

'John learned to identify the murderer of Smith by name'

- For (63b): non-default resolution: $z \rightarrow$ naming $\& y \rightarrow A$, if A salient

'John learned to identify by name the much sought-after criminal known as The Strangler, who in fact (but possibly to John's ignorance) murdered Smith'

Arequipa. Now consider the first exception to Greenberg's generalization, and its possible representations:

(64) Tomas only knew the city we visited on our honeymoon.

a. $\quad K_{t}\left(\uparrow_{(z, P)} l x\right.$. CITY-VISITED-ON-HONEYMOON $\left.\left.(x)\right)\right)$

b. $\quad \exists y \cdot\left(y=l x\right.$.CITY-VISITED-ON-HONEYMOON $(x) \wedge K_{t}\left(\uparrow_{(z, P)} y\right)$

In the described context Tomas has to say which of the cities in a list are capitals and which are not. It is natural to assume that the following covers and properties are available in this context. We underline the values that would involve non-default resolution, in this case the property CAPITAL.
a. Covers: naming
b. Properties: identity, CITY-VISITED-ON-HONEYMOON, CAPITAL

No matter whether we assume the de re or the de dicto representation of (64), the only resolution of $P$ that yields a relevant meaning in this context is the non-default resolution to the property CAPITAL. Given this resolution the sentence could be interpreted as: 'Tomas only knew whether the city that he and Tereza visited on their honeymoon was a capital city or not' (de dicto), or 'Tomas only knew of the city that he and Tereza visited on their honeymoon whether or not it was a capital city' (de re). Before accepting a non-default resolution, however, we have to check whether there is a more perspicuous way to express the obtained meanings in the 
given context. This is not the case here. Therefore, the non-default resolution is licensed. $^{21}$

\section{Summary of predicted resolutions:}

- For (64a): $P \rightarrow$ CAPITAL

[others trivial/irrelevant]

'Tomas only knew whether the city that he and Tereza visited on their honeymoon was a capital city or not'

- For (64b): $P \rightarrow$ CAPITAL \& $y \rightarrow$ naming

[others trivial/irrelevant]

'Tomas only knew of the city that he and Tereza visited on their honeymoon whether or not it was a capital city'

- Blocking check: Is there another more effective way to express these meanings in the given context? No.

The Obamas. Consider the relevant sentence and its possible analyses:

Billy (only) knew your father.

a. $\quad K_{b}\left(\uparrow_{(z, P)} l x\right.$. YOUR-FATHER $\left.(x)\right)$

b. $\quad \exists y \cdot\left(y=l x\right.$. YOUR-FATHER $\left.(x) \wedge K_{b}\left(\uparrow_{(z, P)} y\right)\right)$

In the described context there are two salient covers, the naming cover and the derived presidents cover: \{the president of the United States, the president of Mexico, the president of Venezuela, ... \}. Resolution to the latter cover would be exceptional, since the functional noun 'president' is not contained in the CQ. The available options for $P$ on the other hand, are the identity property and the property expressed by the CQ noun phrase.
a. Covers: naming, presidents
b. Properties: identity, YOUR-FATHER

Assuming the de dicto representation, (66a), any possible resolution yields a trivial meaning $(P \rightarrow$ YOUR-FATHER) or an irrelevant meaning $(P \rightarrow \mathrm{ID})$. As for the de re representation, the only resolution that provides a relevant meaning is the one that maps $P$ to the identity property, $y$ to the derived presidents cover, and $z$ to the naming cover. This is a non-default resolution, so we need to check for the availability of a strictly more efficient way to express the obtained meaning in the given context. A natural candidate is the sentence 'Billy only knew the president of the US' which would convey the same meaning without the need for non-default resolution. However, for independent reasons, it is strongly dispreferred for

\footnotetext{
21 Intuitively, the presence of only in example (64) makes it particularly easy to establish a non-default resolution. This may be explained by the fact that, in the presence of only, default resolution of $P$ to CITYVISITED-ON-HONEYMOON yields the following meaning: 'only of the city visited on their honeymoon, Tomas knew that it was the city they visited on their honeymoon'. This is not merely an irrelevant meaning, but moreover a meaning to which only does not make any essential contribution. For, if there is only one city visited by Tomas and Teresa on their honeymoon, of what other city could Tomas possibly know that it is the city that he and Teresa visited on their honeymoon? Plausibly, this is why the presence of only in (64) makes it particularly clear that a non-default resolution of $P$ is intended.
} 
Michelle Obama to refer to her husband as 'the president of the US' when talking to her daughters. 'Your father' is the preferred referential expression in this context (cf. Gundel et al.1993; Aloni 2001). Therefore, the non-default resolution is licensed in this case.

\section{Summary of predicted resolutions:}

- For (66a): either trivial $[P \rightarrow$ YOUR-FATHER] or irrelevant $[P \rightarrow \mathrm{ID}]$

- For (66b):

$P \rightarrow$ identity

$z \rightarrow$ naming

$y \rightarrow$ presidents

[others trivial/irrelevant]

'Billy could only identify the president of the US by name'

- Blocking check: Is there another more perspicuous way to express this meaning in the given context? No (since, for independent reasons, it is strongly dispreferred for Michelle Obama to refer to her husband as 'the president of the US' when talking to her daughters).

Notice that this example differs from the Arequipa example in that it involves nondefault cover resolution rather than non-default resolution of $P$.

Finally, we turn to Romero's example, which is a case where non-default resolution is blocked by an alternative, more efficient form.

Romero. Consider Romero's example and its two possible representations:

(68) Lucia knows the capital that Ben (already) knows.

a. $\quad K_{l}\left(\uparrow_{\left(z_{1}, P_{1}\right)} l x \cdot\left(\operatorname{CAPITAL}(x) \wedge K_{b}\left(\uparrow_{\left(z_{2}, P_{2}\right)} x\right)\right)\right)$

b. $\exists y\left(y=l x \cdot\left(\operatorname{CAPITAL}(x) \wedge K_{b}\left(\uparrow_{\left(z_{1}, P_{1}\right)} x\right)\right) \wedge K_{l}\left(\uparrow_{\left(z_{2}, P_{2}\right)} y\right)\right)$

The available covers and properties in the given context are:

(69) a. Covers: naming, capitals

b. Properties: identity, CAPITAL-B-KNOWS, CAPITAL-L-KNOWS

As in the previous example, the de dicto representation does not yield any relevant interpretation. As for the de re representation, the only resolution leading to a relevant meaning is the resolution mapping $y$ to the derived capital cover, $P_{1}$ to CAPITAL-LUCIA-KNOWS, $P_{2}$ to the identity property, and $z_{2}$ to the naming cover. Given this resolution, the sentence conveys that Ben already knows the capital that Lucia knows. However, this interpretation involves non-default resolution, so we need to check whether it is blocked. And in this case there is indeed a more perspicuous way to express the relevant meaning, namely the sentence: 'Ben already knows the capital that Lucia knows'. Therefore, the non-default resolution is discarded and the interpretation procedure fails to derive a relevant meaning.

\section{Summary of predicted resolutions:}

- For (68a): all either trivial or irrelevant 
- For (68b):

$P_{1} \rightarrow$ CAPITAL-THAT-LUCIA-KNOWS

$P_{2} \rightarrow$ identity

$y \rightarrow$ capitals

$z_{2} \rightarrow$ naming

'Ben (already) knows the capital that Lucia knows'

[others trivial/irrelevant]

- Blocking check: Is there another more effective way to express this meaning in the given context? Yes.

$\Rightarrow$ the interpretation process fails to derive a relevant meaning

Thus, the proposed constraints on resolution, which were motivated by ideas familiar from Gricean pragmatics, account for Greenberg's and Romero's observations, while preserving enough flexibility to deal with the Arequipa example and the Obama case.

\section{Conclusion}

We have proposed an account of CQs whose central assumption is that an entitydenoting expression $\alpha$ may be type-shifted into an expression ?z. $P(\alpha)$, where $P$ is a contextually determined property, and $z$ ranges over a contextually determined conceptual cover. Thus, depending on the resolution of $P$ and the domain of $z$, a CQ either denotes the true exhaustive answer to the identity question which $z$ is $\alpha$, or to the polar question whether $\alpha$ has the property $P$.

As a final remark, we would like to point out that the account presented here is related to the theory of anaphora proposed in Roelofsen (2008). One of the basic claims of that theory is that the interpretation of NP and VP anaphora, just like that of CQs, crucially involves the contextual resolution of a property $P$. Moreover, $P$ is by default resolved to the property expressed by some overt NP or VP in the surrounding discourse, or to the property of being identical to some bound variable. This is in exact analogy with the default resolution of $P$ in the interpretation of CQs.

\section{A Appendix}

\section{A.1 Distribution of CQs}

Previous work on CQs has not only been concerned with their interpretation, but also with their distribution (see especially Nathan (2006)). One of the main challenges in this area is to characterize the range of verbs that select for CQ complements, as compared to the range of verbs that select for full-fledged declarative and/or interrogative complement clauses. It turns out that this task is far from 
Table 1 A representative sample of the data concerning selection

\begin{tabular}{llll} 
& that-complement & wh-complement & CQ-complement \\
\hline Hope & & $*$ & $*$ \\
Believe & & & $*$ \\
Suspect & & & \\
\hline Agree & & & \\
Inform & & \\
Be certain & & \\
\hline
\end{tabular}

Know
Remember
Forget

Be related to

Depend on

Wonder

Inquire

straightforward. A representative sample of the relevant data, mostly drawn from Baker (1968), Grimshaw (1979), and Nathan (2006), is given in Table $1 .^{22}$

A generalization that emerges from this table is that any verb that selects for CQs also selects for wh-complements (as first observed by Baker (1968)). Otherwise, however, there are no clear correlations between the verbs that select for CQs and the verbs that select for $w h$ - and/or that-complements.

Below we will outline a semantic account of these distributional facts that is compatible with our theory of CQ interpretation. It should be emphasized that our purpose here is just to show that it is in principle possible to develop a semantic account of the relevant distributional facts that is compatible with our theory of CQ interpretation, contrary to what Nathan (2006) and Frana (2010a) may be taken to suggest. An elaborate attempt to adduce independent evidence for all the underlying assumptions, as well as a detailed comparison with alternative accounts (especially that of Nathan (2006)) will be left for a future occasion.

We will proceed as follows. First, we will specify our assumptions concerning the semantic characteristics of CQs, wh-complements, and that-complements. Second, we will introduce a type-shifting operator, ANS, which maps the denotation of a whcomplement in a particular world to the true exhaustive answer to the question expressed by that wh-complement in the given world (such an operator has been argued for independently by, for instance, Heim 1994). Finally, we will specify certain selectional criteria for the verbs appearing in Table 1, and illustrate the predictions of our account with some examples.

\footnotetext{
22 One verb that we intentionally did not include in the table is ask. At first sight, it seems that ask selects for CQ-complements (e.g., Alex asked me the price of milk). However, Nathan (2006, pp. 140-145) argues that such examples are deceptive and that ask does in fact not select for CQ-complements. This claim has remained controversial, but we will not address this issue here.
} 
Table 2 Semantic characteristics of CQ-, wh- and that-complements

\begin{tabular}{lll}
\hline & Denotation & World-dependency \\
\hline CQ-complement & Proposition & + \\
that-complement & Proposition & - \\
wh-complement & Propositional concept & - \\
\hline
\end{tabular}

Semantic characteristics of CQ-, wh- and that-complements. On the account developed in this paper, CQs denote propositions. But this is not the only semantic feature of CQs that may be relevant for selection. Another potentially relevant semantic feature of CQs is that they typically denote different propositions in different worlds. That is, the denotation of CQs is world-dependent. CQs crucially differ in this respect from that-complements. The latter denote propositions as well, but their denotation is the same in every world. Thus, the denotation of thatcomplements is world-independent. Finally, we will assume that wh-complements denote propositional concepts rather than propositions. More specifically, we will assume that $w h$-complements denote functions from possible worlds to true exhaustive answers, or equivalently partitions of the logical space in the sense of Groenendijk and Stokhof (1984). Recall, though, that Groenendijk and Stokhof originally assumed that the intension of a wh-complement is a propositional concept (or equivalently a set of propositions partitioning logical space), while the extension (i.e., the denotation) of a $w h$-complement in a particular world is a proposition. Here, a wh-complement is taken to denote a propositional concept, namely the propositional concept that Groenendijk and Stokhof take to be its intension. ${ }^{23,24}$ This means that the denotation of a wh-complement is world-independent. Our assumptions are summarized in Table 2.

The ans operator. Given the above assumptions, wh-complements differ in semantic type from that- and CQ-complements. However, as mentioned in Section 2, wh-complements can be coordinated with that-complements and with CQ-complements; the relevant examples are repeated below.

(70) Julia remembers what Ben ate and that he didn't like it.

\footnotetext{
23 One way of implementing this would be to represent a wh-complement like who has the property $P$ as $\wedge$ ? $x . P(x)$, using the ${ }^{\wedge}$ operator from Montague grammar.

24 The assumption that $w h$-complements denote propositional concepts is made here for concreteness, but it is not crucial for our account. Alternatively, we could follow Karttunen (1977a) in assuming that the denotation of an interrogative clause in a given world is the set of propositions that correspond to the most basic true answers to that interrogative clause in that world. In this case, the denotation of an interrogative clause would be world-dependent. Or we could follow Hamblin (1973) in assuming that the denotation of an interrogative clause in a given world is the set of propositions that simply correspond to the most basic answers (not necessarily true answers) to the given interrogative clause. In this case, the denotation of an interrogative clause would again be world-independent. If we were to adopt Hamblin's or Karttunen's analysis of interrogative clauses, we would have to adapt the definition of the Ans operator given in (72) below, and the selectional criteria of agree-type and wonder-type verbs.
} 
Table 3 Selectional criteria for the verbs in Table 1

\begin{tabular}{ll}
\hline Verb & Selects for complements that denote \\
\hline Hope & A world-independent proposition \\
Believe & \\
Suspect & A world-independent (proposition or propositional concept) \\
\hline Agree & \\
Inform & \\
Be certain & \\
\hline
\end{tabular}

Know A proposition

Remember

Forget

Be related to

A world-dependent proposition

Depend on

Wonder A propositional concept

Inquire

(71) I only knew the capital of Italy and who won the Worldcup in 1986.

To derive the meaning of such sentences we will assume, following Heim (1994) and others, an operator ANS which applies to an interrogative clause and delivers the true exhaustive answer to that interrogative clause in the world of evaluation. The operator is defined as follows. ${ }^{25}$

(72) For any expression $\varphi$ of type $s(s t)$ : $\llbracket$ ANs $\varphi \rrbracket_{M, w, g_{\mathcal{R}}}=\llbracket \varphi \rrbracket_{M, w, g_{\mathcal{R}}}(w)$

【ANS $\varphi \rrbracket_{M, w, g_{\mathcal{R}}}$ is a proposition that embodies the true exhaustive answer in $w$ to the question that $\varphi$ expresses. Notice that $\llbracket$ ANS $\varphi \rrbracket_{M, w, g_{\mathcal{R}}}$ typically differs from world to world. This means that the denotation of ANS $\varphi$ is world-dependent.

The ANS operator allows us to account for the coordination facts mentioned above. Moreover, it also allows us to assume a single lexical entry for verbs that select for both that-complements and wh-complements. For instance, to deal with sentences like (73) and (74), we just need to assume a single lexical entry for tell:

(73) Max told us who called.

(74) Max told us that Bill called.

\footnotetext{
25 Note that our ANS operator is quite different from the one that is used in Romero's (2007) account of concealed questions. Our ANS operator takes a propositional concept and delivers a proposition, while Romero's ANS operator takes an individual concept and yields a propositional concept. Moreover, Romero's ANS operator plays a crucial role in the interpretation of CQ-complements, while our ANS operator does not play a role for CQ-complements at all; rather, it may play a role in the interpretation of wh-complements.
} 
Without the ANS operator, we would have to assume two lexical entries for tell, one that takes that-complements and one that takes wh-complements.

Selectional criteria for embedding verbs. The selectional criteria that we assume for the verbs in Table 1 are specified in Table 3.

Illustration of predictions. Under the given assumptions, the observed distributional patterns are suitably accounted for. To see this, let us consider one verb from each of the five rows in Table 1. First consider the verb believe, from the first row, which only selects for that-complements:

(75) Alex believes that he paid/*who paid/*the price of milk.

We are assuming that believe selects for complements that denote a worldindependent proposition. This criterion is indeed satisfied by that-complements, but not by CQ- or wh-complements, even after application of ANS.

Next consider the verb agree, which selects for that- and wh-complements, but not for CQ-complements:

(76) They agreed that he would pay/who would pay/*the price of milk.

We are assuming that agree selects for complements that denote a worldindependent proposition or propositional concept. This criterion is satisfied by thatcomplements and by wh-complements (without application of ANs), but not by CQ-complements.

Next consider remember, which selects for all three types of complements:

Alex remembered that he paid/who paid/the price of milk.

We are assuming that remember selects for complements that denote a proposition, world-dependent or -independent, and this criterion is indeed satisfied by all three types of complements. In the case of a wh-complement, application of ANS is necessary before the complement combines with the verb.

Now consider depend on, which selects for wh- and CQ-complements:

(78) Alex's mood depends on *that he paid/who paid/the price of milk.

We are assuming that depend on selects for complements that denote a worlddependent proposition, and this criterion is indeed satisfied by CQ- and whcomplements, after application of ANs, but not by that-complements.

Finally, consider the verb wonder, which only selects for wh-complements:

Alex is wondering *that he paid/who paid/*the price of milk.

We are assuming that wonder selects for complements that denote a propositional concept. This criterion is satisfied by wh-complements, without application of ANS, but not by that- or CQ-complements. Thus, all the relevant data are accounted for. 


\section{A.2 Derived covers}

An anonymous reviewer pointed out a potential problem arising for de dicto representations of definite CCQs, exemplified in (80).

(80) a. John knows the price that Fred knows.

b. $\quad K_{j}\left(\uparrow_{\left(z_{1}, P_{1}\right)} l x .\left(\operatorname{PRICE}(x) \wedge K_{f}\left(\uparrow_{\left(z_{2}, P_{2}\right)} x\right)\right)\right)$

Consider the following resolution:

- $x, z_{1} \rightarrow\{$ price of milk, price of wine, price of butter, ...

- $z_{2} \rightarrow\{€ 1, € 2, € 3, \ldots\}$

- $P_{1} \rightarrow \lambda y \cdot y=z_{1}$

- $P_{2} \rightarrow \lambda y \cdot y=z_{2}$

Under this resolution, the truth-conditions for (80b) are too weak: (80a) is predicted to be true in certain scenarios where it is intuitively false. To see this, consider the two scenarios in (81). While sentence (79a) is intuitively false in scenario A, but true in scenario $\mathrm{B},(79 \mathrm{~b})$ fails to distinguish between the two scenarios and predicts the sentence to be true in both cases.

(81) Scenario A: Milk and butter both cost €2, and nothing else costs $€ 2$. John does not know how much milk or butter costs, but he knows that they cost the same. Fred knows that the price of milk is $€ 2$, but he does not know what the price of butter is. John is aware that the price that Fred knows the euro-value of is either the price of milk, or the price of butter, but John cannot determine which one of those two it is.

Scenario B: Just like scenario A, but now John knows that Fred knows the price of milk.

As a formal representation of the two scenarios, consider a model consisting of the following four worlds:

\begin{tabular}{lll}
\hline & Milk & Butter \\
\hline$w_{0}$ & 2 & 2 \\
$w_{1}$ & 1 & 1 \\
$w_{2}$ & 1 & 2 \\
$w_{3}$ & 2 & 1 \\
\hline
\end{tabular}

and assume the following specifications for John's and Fred's epistemic states:

(82) Scenario A:

a. $E\left(j, w_{0}\right)=\left\{w_{0}, w_{1}\right\}$ (in $w_{0}$ John doesn't know the price of milk or butter, but he knows that they are the same) 

b. $E\left(f, w_{0}\right)=\left\{w_{0}, w_{2}\right\}$ (in $w_{0}$ Fred knows the price of butter)
c. $E\left(f, w_{1}\right)=\left\{w_{1}, w_{2}\right\}$ (in $w_{1}$ Fred knows the price of milk)

\section{Scenario B:}

a. $E\left(j, w_{0}\right)=\left\{w_{0}, w_{1}\right\}$ (as above)

b. $E\left(f, w_{0}\right)=\left\{w_{0}, w_{3}\right\}$ (in $w_{0}$ Fred knows the price of milk)

c. $E\left(f, w_{1}\right)=\left\{w_{1}, w_{2}\right\}$ (as above)

It is easy to see that (80b) is predicted to be true in $w_{0}$ in both scenarios. In particular, the analysis wrongly predicts that in scenario A, John knows in $w_{0}$ which price Fred knows. The problem is that, even though intuitively in the two epistemic alternatives for John in $w_{0}$, namely $w_{0}$ and $w_{1}$, Fred knows different prices (the price of butter in $w_{0}$ and the price of milk in $w_{1}$ ), these two concepts (the price of butter and the price of milk) have exactly the same values in both alternatives in John's epistemic state (he believes that they are extensionally equivalent), and therefore they count as one; so John knows of that one concept, which is an element of the price cover, that Fred knows its euro-value.

The source of the problem seems to be that our system allows for derived covers, which typically contain overlapping individual concepts like 'the price of butter' and 'the price of milk' (these concepts are overlapping in the sense that in some worlds they have exactly the same value). In certain epistemic states such concepts will be indistinguishable, because they have the same value in all relevant worlds.

One way to avoid this problem would be to construe a derived cover not just as a set of individual concepts, but rather as a more structured object, for instance a pair consisting of a basic cover and an intensional function that maps, say, every object in every world to the price of that object in that world, if any. This way, the elements of a derived cover will always be clearly distinguishable: even though their values may overlap in certain worlds, we would always be able to detect that these values were obtained in different ways (e.g., by applying the price-function to butter, or by applying the price-function to milk). However, a full implementation of this solution must be left for another occasion.

It is also worth remarking that the spurious reading discussed here arises from a de dicto treatment of CCQ noun phrases, and that, in the analysis presented in this paper, de dicto representations are not really necessary to obtain any of the observed readings. In particular, they are not really needed to obtain B-readings of CCQs.

Below is a de re representation of the $\mathrm{B}$ reading of our sentence, together with a resolution of the relevant covers and properties, which yields the right predictions for both scenarios (because now we can no longer ignore the values of the relevant concepts in worlds outside of John's epistemic state):

(84) a. John knows the price that Fred knows.

b. $\quad \exists y \cdot\left(y=l x .\left(\operatorname{PRICE}(x) \wedge K_{f}\left(\uparrow_{\left(z_{1}, P_{1}\right)} x\right)\right) \wedge K_{j}\left(\uparrow_{\left(z_{2}, P_{2}\right)} y\right)\right)$

(85) Resolution

a. $x, y \rightarrow\{$ price of milk, price of wine, price of butter, ... 

b. $\quad z_{1} \rightarrow\{€ 1, € 2, € 3, \ldots\}$
c. $\quad P_{1} \rightarrow \lambda y \cdot y=z_{1}$
d. $\quad P_{2} \rightarrow \lambda x \cdot \operatorname{PRICE}(x) \wedge K_{f}\left(? z_{1} \cdot P_{1}(x)\right)$

Thus, another way to avoid the spurious reading discussed above would be to ban $d e$ dicto representations altogether. But can this be justified in the grammar? Is there a principled way to prevent CQ noun phrases from being interpreted in situ? Again, we must leave these questions for another occasion.

\section{A.3 Non-factive verbs}

Another potential issue for our analysis, also pointed out by an anonymous reviewer, concerns predicational readings of quantified CQs under non-factive verbs like agree on. For example, according to the reviewer, a sentence like (86) would be true on its predicational reading in a scenario like (87), while on our analysis it would come out false, because quantified CQs need to scope out of the verb, and (86) would therefore be analyzed as 'for most actual phone numbers, John and Mary agree on whether they are phone numbers', which is false in the given scenario.

(86) John and Mary agree on most phone numbers.

(87) Scenario:

a. Salient list of potential phone numbers:

101, 102, 103, 104, 105

b. Actual phone numbers:

$101,102,103$

c. Numbers that John believes to be phone numbers: 101, 103, 104, 105

d. Numbers that Mary believes to be phone numbers: $102,103,104,105$

Intuitions on this example are far from clear. Does the CQ in (86) really quantify over salient numbers (as assumed by the reviewer) rather than actual phone numbers (as predicted by our analysis)? Consider the following case. Two lunatics, John and Mary, believe that some of their friends, namely Sue, Bill and Fred, are werewolves, and that there are no other werewolves. It seems appropriate to describe this situation with (88a), but not with (88b).

(88) a. John and Mary agree on which of their friends are werewolves.

b. John and Mary agree on every werewolf.

One potential reason for the awkwardness of (88b) is that the quantified CQ in this sentence quantifies over actual werewolves (as predicted by our analysis), and therefore violates a principle against vacuous quantification. However, further investigation of this issue must be left for another occasion. 
Open Access This article is distributed under the terms of the Creative Commons Attribution License which permits any use, distribution, and reproduction in any medium, provided the original author(s) and the source are credited.

\section{References}

Aloni, M. (2001). Quantification under conceptual covers. Ph.D. thesis, University of Amsterdam.

Aloni, M. (2008). Concealed questions under cover. Grazer Philosophische Studien, 77, 191-216. Special issue on Knowledge and Questions edited by Franck Lihoreau.

Baker, C. (1968). Indirect questions in English. Ph.D. thesis, University of Illinois.

Fox, D. (1999). Focus, parallelism and accommodation. In Proceedings of Semantics and Linguistic Theory IX.

Frana, I. (2006). The de re analysis of concealed questions. In C. Tancredi, M. Kanazawa, I. Imani, \& K. Kusumoto (Eds.), Proceedings of Semantics and Linguistic Theory XVI.

Frana, I. (2010a). Concealed questions. In search of answers. Ph.D. thesis, UMass Amherst.

Frana, I. (2010b). Copular questions and concealed questions. In M. Prinzhorn, V. Schmitt, \& S. Zobel (Eds.), Proceedings of Sinn und Bedeutung 14. Vienna: University of Vienna.

Greenberg, B. (1977). A semantic account of relative clauses with embedded question interpretations. Manuscript, UCLA.

Grimshaw, J. (1979). Complement selection and the lexicon. Linguistic Inquiry, 10, 279-326.

Groenendijk, J., \& Stokhof, M. (1984). Studies on the semantics of questions and the pragmatics of answers. Ph.D. thesis, University of Amsterdam.

Gundel, J., Hedberg, N., \& Zacharski, R. (1993). Cognitive status and the form of referring expressions in discourse. Language, 69(2), 274-307.

Hamblin, C. L. (1973). Questions in Montague English. Foundations of Language, 10, 41-53.

Harris, J. (2007). Revealing concealment: A (neuro-) logical investigation of concealed questions. MSc thesis, University of Amsterdam.

Heim, I. (1979). Concealed questions. In R. Bäuerle, U. Egli, \& A. von Stechow (Eds.), Semantics from different points of view. Berlin: Springer.

Heim, I. (1994). Interrogative semantics and Karttunen's semantics for know. In R. Buchalla \& A. Mittwoch (Eds.), The proceedings of the Ninth Annual Conference of the Israel Association for Theoretical Linguistics. Jerusalem: Academon.

Heim, I. (1997). Predicates or formulas? Evidence from ellipsis. In A. Lawson (Ed.), Proceedings of the seventh conference on semantic and linguistic theory (pp. 197-221). Ithaca, NY: Cornell University.

Heim, I. (2009). Nouns as predicates of individual concepts? Handout presented at the frequently asked concealed questions workshop in Göttingen.

Karttunen, L. (1977a). Syntax and semantics of questions. Linguistics and Philosophy, 1, 3-44.

Karttunen, L. (1977b). To doubt whether. The CLS book of squibs. Chicago: Chicago Linguistics Society.

Nathan, L. (2006). On the interpretation of concealed questions. Ph.D. thesis, MIT.

Percus, O. (2010). Uncovering the concealed question (and some shifty types). Handout presented at Semantics and Linguistic Theory XX.

Roelofsen, F. (2008). Anaphora resolved. Ph.D. thesis, University of Amsterdam.

Roelofsen, F., \& Aloni, M. (2008). Perspectives on concealed questions. In T. Friedman \& S. Ito (Eds.), Proceedings of semantics and linguistic theory XVIII. Ithaca, NY: Cornell University

Romero, M. (2005). Concealed questions and specificational subjects. Linguistics and Philosophy, 28(5), $687-737$.

Romero, M. (2007). Connectivity in a unified analysis of specificational subjects and concealed questions. In C. Barker \& P. Jacobson (Eds.), Direct compositionality. Oxford: Oxford University Press.

Romero, M. (2010). Concealed questions with quantifiers. In M. Aloni, H. Bastiaanse, T. de Jager, \& K. Schulz (Eds.), Logic, Language, and Meaning: Selected and revised papers from the Amsterdam Colloquium (pp. 21-31). Berlin: Springer.

Rooth, M. (1992). Ellipsis redundancy and reduction redundancy. In S. Berman \& A. Hestvik (Eds.), Proceedings of the Stuttgart workshop on ellipsis.

Schwager, M. (2007a). Bodyguards under cover: The status of individual concepts. In M. Gibson \& T. Friedman (Eds.), Proceedings of semantics and linguistic theory XVII. Ithaca, NY: Cornell University.

Schwager, M. (2007b). Keeping prices low: An answer to a concealed question. In A. Gronn (Ed.), Proceedings of Sinn und Bedeutung XII. Oslo: University of Oslo. 